\title{
Correlates of Attitude Towards Amyotrophic Lateral Sclerosis among Health Care Students - A Cross-sectional Study Findings
}

\author{
Muhammad Zahid Iqbal', Salah-Ud-Din Khan², Muhammad Shahid Iqbal ${ }^{3, *}$ \\ 'Department of Clinical Pharmacy and Pharmacy Practice, Faculty of Pharmacy, AIMST University, Bedong, Kedah Darul Aman, MALAYSIA. \\ 2Department of Biochemistry, College of Medicine, Al-Imam Mohammad Ibn Saud Islamic University, Riyadh, SAUDI ARABIA. \\ 3Department of Clinical Pharmacy, College of Pharmacy, Prince Sattam bin Abdulaziz University, Al-Kharj, 11942, SAUDI ARABIA.
}

\begin{abstract}
Objectives: To evaluate correlated factors (correlates) of attitude towards Amyotrophic Lateral Sclerosis (ALS) among health care students in a medical university. Methods: A stratified convenient sampling technique was used to calculate the sample size for the current study in three different health care faculties. A pre-validated and self-developed questionnaire was used for data collection of the present study. The Statistical Package for Social Sciences (SPSS) version 24.0 was utilized for data analysis and the interpretation of the results with the help of both descriptive and inferential statistics. Results: A total of 268 health care students from three faculties (medical, pharmacy and dental) participated in the current study. In univariate analysis, a statistical significance $(p<0.05)$ was observed in all of the studied variables. Conversely, in multivariate logistic regression model, gender, faculty, year of education and residence variables were observed
\end{abstract}

as statistically significant $(p<0.05)$. Conclusion: This study confirmed that gender, faculty, year of education and residence were the correlates (pure) of the attitude towards ALS among health care students of a medical university in Malaysia.

Key words: Amyotrophic Lateral Sclerosis, ALS, Health care students, Attitude, Correlates.

\section{Correspondence}

Dr. Muhammad Shahid Iqbal

Department of Clinical Pharmacy, College of Pharmacy, Prince Sattam bin Abdulaziz University, Al-Kharj, 11942, SAUDI ARABIA.

Phone no: +966-53-7014420

Email: drmmsiabal@gmail.com

DOI: 10.5330/ijpi.2020.4.105

\section{INTRODUCTION}

Amyotrophic lateral sclerosis (ALS) is a disorder that belongs to the uncommon neurological disease classification. ${ }^{1}$ ALS generally affects the nerve cells that liable for regulating voluntary muscular movements. ${ }^{2}$ Voluntary muscles generate some activities like chewing, talking and walking as well. ALS is a progressive disease and the symptoms get worse over time. ${ }^{3}$ At present, there is no cure available for ALS and no effective treatment to stop or reverse the disease's progression in patients. ALS is directly responsible for the degeneration and the death of motor neurons. ${ }^{4,5}$ Thus, in ALS patients, due to the deterioration of motor neurons in the upper and lower nerves, the transferring of messages to the muscles stops. ${ }^{6}$ As a result of this deterioration, the function and muscles' forces are gradually weakening, starting to twitch and finally resulting in atrophy. Ultimately, the brain loses its capability to instigate and regulate voluntary movements. ${ }^{7}$

A timely diagnosis of ALS is essential in patients to decrease disease progression. ${ }^{8}$ The ALS's initial markers include the increase in muscle cramps, muscle weakness and trouble in moving around or performing regular daily activities. ${ }^{9}$ A considerable problem in ALS diagnosis is the absence of these biomarkers, which results in a delay in diagnosis up to 12 months and leads to a false diagnosis in about $10 \%$ of ALS patients. ${ }^{9,10}$ Complications associated with ALS delayed diagnosis contain difficulties in speaking, breathing and eating. Conversely, respirational failure in ALS patients is the most common cause of death among patients of this disease. $^{11}$

Until now, suitable and specific treatment is not available for ALS, but Riluzole is believed as one of the FDA endorsed drug that can slow down ALS progression and improve the quality of life of the patients. ${ }^{12}$ Riluzole lowers the glutamate level that is generally high in ALS patients. ${ }^{13}$ Though ALS is a well-known disorder, yet health care students may not have proper awareness of it as no study is evident in literature regarding determination of correlates of attitude towards ALS among health care students in Malaysia. The present study aimed to determine correlates of attitude towards ALS among health care students of a medical university in Malaysia.

\section{MATERIALS AND METHODS}

A cross-sectional study was performed among the health care students using a pre-validated research questionnaire. The validated questionnaire consists of two parts. The first part was the demographics of the respondents, whereas the second part was the attitude questions. The response to each attitude question was taken on a five-point Likert scale. The criteria for attitude securing were adapted by an earlier similar study. ${ }^{14}$

The sample size of the current study was calculated using a stratified convenience sampling technique. The targeted sample size was 250 and 268 responses were collected from students of three health care faculties. The informed consent was taken from all the participants before participating in the current study.

\section{Statistical analyses}

Statistical Package for Social Science (SPSS) version 24.0 was applied to analyze and present data. Frequencies with percentages were considered and presented as categorical variables of the current study. The Pearson Chi-Square/ Fisher's Exact Test was applied to get the $p$-value among variables in univariate analysis. A $p$-value less than 0.05 was considered as statistically significant. Phi Cramer's value was identified to get the effect size of the statistically significant variables. The gained scores 
were interpreted as a percentage response to ease the data presentation. The results interpretation of effect size was as according to the Crohn's classification for categorical data. Those variables which were statistically significant $(p<0.05)$ in univariate analysis were further analyzed under multivariate analysis using multiple logistic regression to determine the pure correlates of attitude towards ALS among health care students of the study site.

\section{RESULTS}

A total of 268 health care students from three faculties (medical, pharmacy and dental) participated in the current study. The demographics studied were gender, race, faculty, age, year of education, residence and educational background. The demographic variables are presented in Figure 1.

In univariate analysis, a statistically significant $(p<0.05)$ association was observed in all the variables. The results are presented in Table 1. A statistically significant and medium association was observed between gender $(p=0.007, \varphi=0.121)$ and faculty $(p=0.003, \varphi=0.126)$ variables whereas all other variables had a statistically significant but weak association.

Table 2 presents the results of multivariate analysis where gender, faculty, year of education and residence were observed as correlates of attitude towards ALS among health care students.

\section{DISCUSSION}

The current study is the pioneer study conducted in any medical university in Malaysia that evaluated correlates of attitudes of health care students about ALS. In univariate analysis, the present study found a statistically significant $(p<0.05)$ positive association among all of the variables. The variables included were gender, race, faculty, age, year of education, residence and educational background. A statistically significant and medium association was observed between gender $(p=0.007, \varphi=0.121)$ and faculty $(p=0.003, \varphi=0.126)$ variables. On the other hand race

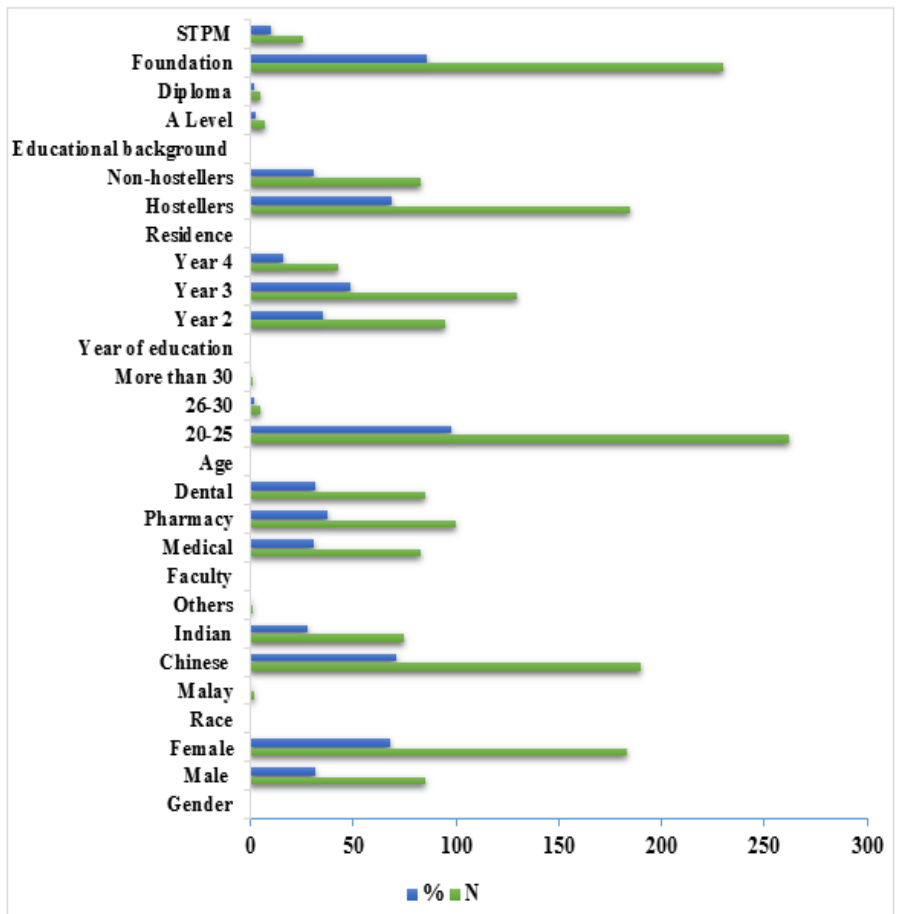

Figure 1: Demographic information of respondents $(\mathrm{N}=268)$. STPM = Malaysian Higher School Certificate
( $p=0.041, \varphi=0.019)$, age $(p=0.038, \varphi=0.013)$, year of education $(p=0.002$, $\varphi=0.076$ ), education background ( $p=0.047, \varphi=0.014)$ had statistically significant but weak associations. On the other hand, residence $(p<0.001$, $\varphi=0.329)$ had a statically significant and strong association among the studied participants.

The present study's findings proved that the female students had a more positive attitude $(65.0 \%)$ compared to the male students $(54.1 \%)$. A statistically significant difference $(p=0.007)$ was observed with a medium positive association $(\phi=0.121)$ in the gender variable. The proposed reason behind this could be a positive attitude of females towards patients care than males. These current study findings are in line regarding attitude with another study conducted in Malaysia regarding Japanese Encephalitis among health care students where female students had a more positive attitude compared to males. ${ }^{15}$ Likewise, another study also reported that female students had better perception than males but that study was also performed for another disease. ${ }^{16}$

Table 1: Correlates of attitude towards ALS by univariate analysis.

\begin{tabular}{|c|c|c|c|c|c|}
\hline \multirow{2}{*}{ Variables } & \multicolumn{3}{|c|}{ Attitude } & \multirow{2}{*}{$p$-Value } & \multirow{2}{*}{$\begin{array}{l}\text { Effect } \\
\text { size\# }\end{array}$} \\
\hline & Negative & Neutral & Positive & & \\
\hline \multicolumn{6}{|c|}{ Gender } \\
\hline Male & $15(17.6)$ & $24(28.2)$ & $46(54.1)$ & $0.007^{*}$ & 0.121 \\
\hline Female & $5(2.7)$ & $59(32.2)$ & $119(65.0)$ & & \\
\hline \multicolumn{6}{|c|}{ Race } \\
\hline Malay & 0 & $1(50.0)$ & $1(50.0)$ & $0.011^{\star}$ & 0.019 \\
\hline Chinese & $11(5.8)$ & $23(12.1)$ & $156(82.1)$ & & \\
\hline Indian & $8(10.7)$ & $18(24.0)$ & $49(65.3)$ & & \\
\hline Others & 0 & $1(100.0)$ & 0 & & \\
\hline \multicolumn{6}{|c|}{ Faculty } \\
\hline Medical & $8(9.6)$ & $24(28.9)$ & $51(61.5)$ & $0.003^{*}$ & 0.126 \\
\hline Pharmacy & $4(4.0)$ & $37(37.0)$ & $59(59.0)$ & & \\
\hline Dental & $9(10.6)$ & $28(32.9)$ & $48(56.5)$ & & \\
\hline \multicolumn{6}{|c|}{ Age } \\
\hline $20-25$ & $29(11.1)$ & $56(21.4)$ & $177(67.5)$ & $0.038^{*}$ & 0.013 \\
\hline $26-30$ & $1(20.0)$ & $1(20.0)$ & $3(60.0)$ & & \\
\hline More than 30 & 0 & $1(100.0)$ & 0 & & \\
\hline \multicolumn{6}{|c|}{ Year of education } \\
\hline Year 2 & $15(15.8)$ & $37(38.9)$ & $43(45.3)$ & $0.002^{*}$ & 0.076 \\
\hline Year 3 & $8(6.2)$ & $24(18.5)$ & $98(75.4)$ & & \\
\hline Year 4 & $2(4.6)$ & $5(11.6)$ & $36(83.7)$ & & \\
\hline \multicolumn{6}{|c|}{ Residence } \\
\hline Hostellers & $7(3.8)$ & $61(33.0)$ & $117(63.2)$ & $<0.001^{*}$ & 0.329 \\
\hline $\begin{array}{c}\text { Non- } \\
\text { hostellers }\end{array}$ & $13(15.7)$ & $21(25.2)$ & $49(59.1)$ & & \\
\hline \multicolumn{6}{|c|}{ Educational background } \\
\hline A Level & 0 & $2(28.6)$ & $5(71.4)$ & $0.047^{\star}$ & 0.014 \\
\hline Diploma & 0 & $2(40.0)$ & $3(60.0)$ & & \\
\hline Foundation & $13(5.7)$ & $28(12.2)$ & $189(82.1)$ & & \\
\hline STPM & $3(11.5)$ & $5(19.3)$ & $18(69.2)$ & & \\
\hline
\end{tabular}

${ }^{\star}$ Pearson Chi-Square/ Fisher's Exact Test

\#Phi Cramer's V

Effect size was measured using Partial Eta Squared ( $\eta 2$ )

According to Cohen's classification of effect size, if $0.01 \leq \eta 2 \leq 0.06=$ small, if $0.06 \leq \eta 2 \leq 0.14=$ medium, $\eta 2 \geq 0.14=$ large 
Table 2: Correlates of attitude towards ALS by multivariate analysis.

\begin{tabular}{|c|c|c|c|c|c|c|}
\hline \multirow[t]{2}{*}{ Variables } & \multirow[t]{2}{*}{$\beta$} & \multirow[t]{2}{*}{ SE } & \multirow{2}{*}{$\begin{array}{l}\text { Adjusted } \\
\text { OR }\end{array}$} & \multicolumn{2}{|c|}{$95 \% \mathrm{Cl}$} & \multirow[t]{2}{*}{$p$-Value } \\
\hline & & & & Lower & Upper & \\
\hline \multicolumn{7}{|l|}{ Gender } \\
\hline Male & Referent & & & & & \\
\hline Female & 0.321 & 0.420 & 1.511 & 0.822 & 2.421 & $0.043^{*}$ \\
\hline \multicolumn{7}{|l|}{ Race } \\
\hline $\begin{array}{l}\text { Malay } \\
\text { (Referent) }\end{array}$ & Referent & & & & & \\
\hline Chinese & 0.860 & 0.384 & 0.561 & 0.395 & 0.923 & 0.059 \\
\hline Indian & 0.740 & 0.421 & 0.651 & 0.421 & 0.843 & 0.052 \\
\hline Others & $\mathrm{NA}^{*}$ & & & & & \\
\hline \multicolumn{7}{|l|}{ Faculty } \\
\hline Medical & Referent & & & & & \\
\hline Pharmacy & 0.879 & 0.418 & 1.281 & 0.761 & 2.549 & $0.027^{*}$ \\
\hline Dental & 0.761 & 0.398 & 1.371 & 0.815 & 2.219 & $0.045^{*}$ \\
\hline \multicolumn{7}{|l|}{ Age } \\
\hline $20-25$ & Referent & & & & & \\
\hline $26-30$ & NA & & & & & \\
\hline More than 30 & NA & & & & & \\
\hline \multicolumn{7}{|l|}{$\begin{array}{l}\text { Year of } \\
\text { education }\end{array}$} \\
\hline Year 2 & Referent & & & & & \\
\hline Year 3 & 0.898 & 0.542 & 2.173 & 0.830 & 3.831 & $0.032^{*}$ \\
\hline Year 4 & 0.787 & 0.439 & 1.981 & 0.789 & 2.692 & $0.042^{*}$ \\
\hline \multicolumn{7}{|l|}{ Residence } \\
\hline Hostellers & Referent & & & & & \\
\hline $\begin{array}{l}\text { Non- } \\
\text { hostellers }\end{array}$ & 0.986 & 0.457 & 0.765 & 0.431 & 2.981 & $0.021^{*}$ \\
\hline \multicolumn{7}{|l|}{$\begin{array}{l}\text { Educational } \\
\text { background }\end{array}$} \\
\hline A Level & Referent & & & & & \\
\hline Diploma & NA & & & & & \\
\hline Foundation & 0.292 & 0.484 & 1.184 & 0.671 & 2.112 & 0.069 \\
\hline STPM & 0.399 & 0.412 & 1.098 & 0.881 & 2.650 & 0.074 \\
\hline
\end{tabular}

$\mathrm{SD}=$ Standard Deviation, $\mathrm{OD}=$ Odds Ratio, $\mathrm{CI}=$ Confidence Interval, $\mathrm{SE}=$ Standard Error, $\beta=$ Beta Coefficient, NA= The assumptions were not met.

A statistically significant $(p=0.041)$ and weak positive association $(\phi=0.019)$ was observed between the respondents' race and the attitude about ALS. The Chinese students in the present study showed a more positive attitude than the other races. The reason behind could be the number of Chinese students was more than other races of the respondents. These findings of the current study supported by a study conducted in Malaysia in 2020, according to which Chinese students had a more positive attitude with better knowledge as compared with the other races in the study. ${ }^{17}$ The results of the current research on the imbalanced number of contestant students were also in line with a survey conducted in Sri Lanka. ${ }^{18}$ Provided at the right time is essential for improving mortality in medical emergencies. Accurate knowledge and skills on this regard, in all medical personals is an essential part of medical education and it should be up to date with varying protocols. The aim of this study is to assess the knowledge and attitudes among the undergraduate medical students and medical officers in the Teaching Hospital Peradeniya and provide suggestions to improve the training programme on ALS. Methods: A standardized self-administered questionnaire regarding knowledge and attitudes on ALS was filled by 4th and final year medical students, and medical officers, and the data was analyzed. Results: There were 411 eligible candidates and of them $130(31.6 \%)$

A statistically significant $(p=0.003)$ association was also observed in the faculty variable with a medium positive association $(\phi=0.126)$ for the attitude regarding ALS. Pharmacy students had a more positive attitude than the other faculties. A similar kind of study findings were also reported by a study conducted in Malaysia on oral health disorders among health care students in which the pharmacy students showed a more positive attitude than the rest of the participants. ${ }^{17}$ This justification and findings of the current study were also well supported by a study conducted in Nepal where the attitude of the pharmacy students was more positive than others. ${ }^{16}$

A statistically significant $(p=0.038)$ and weak positive association ( $\phi=0.013$ ) was observed between the respondents' age and respondents' attitude about ALS. The students 20-25 years of age had a more positive attitude as compared with other age groups in the present study. The reason behind this could be the same as reported in the race determinant, i.e. the imbalanced number of respondents in each age subgroup. The current study also reported a statistical significance $(p=0.002)$ between the year of education variable and the attitude towards ALS. As the year of education increased, the attitude of respondents regarding ALS became more positive. ${ }^{19}$

A statistically significant $(p<0.001)$ and strong positive association $(\phi=0.329)$ was observed between the residence variable with the attitude of respondents on ALS. The reason behind could be the better knowledge of hostelers compared to non-hostelers. This justification was also reported earlier by a study conducted whereby the students who were living in hostels can share their knowledge about any disease with their mates than the non-hostelers. ${ }^{20}$ The present study results were also in line with another study where students living together in hostels can share their knowledge with their fellow friends. ${ }^{20}$

For determination of pure correlates of attitude towards ALS, in multivariate analysis, gender, faculty, year of education and residence were observed as pure correlates $(p<0.05)$ of attitude towards ALS among the studied cohort of the health care students. And race, age and educational background were observed as statistically nonsignificant ( $p>0.05$ ). Among the observed correlates (pure), the gender (AOR 1.511; $p=0.043$ ), faculty of pharmacy (AOR $1.281 ; p=0.027$ ), faculty of dentistry (AOR 1.371; $p=0.045$ ), year of education for year 3 (AOR 2.173; $p=0.032)$ and year $4($ AOR $1.981 ; p=0.042)$ and residence (AOR 0.765; $p=0.021$ ) were reported when adjusted for the other studied demographic variables. There were certain limitations related to the present study, like study was single-centered, cross-sectional and reported self-perceptions about ALS attitude.

\section{CONCLUSION}

The present study reported that gender, faculty, year of education and residence were the pure correlates of attitude towards ALS among the studied sample of the health care students which are future health care providers in Malaysia.

\section{ACKNOWLEDGEMENT}

The authors would like to thank the Deanship of Scientific Research at Prince Sattam bin Abdulaziz University, Al-Kharj, Saudi Arabia, to 
support the publication of this manuscript. The authors would also like to express sincere gratitude to all the participants involved in this study.

\section{CONFLICT OF INTEREST}

The authors declare no Conflict of interest.

\section{ABBREVIATIONS}

ALS: Amyotrophic Lateral Sclerosis; FDA: Food and Drug Administration; SPSS: Statistical Package for Social Sciences; SD: Standard Deviation; CI: Confidence Interval; OR: Odds Ratio; AOR: Adjusted Odds Ratio.

\section{REFERENCES}

1. Fecto F, Yan J, Vemula SP, Liu E, Yang Y, Chen W, et al. SQSTM1 mutations in familial and sporadic amyotrophic lateral sclerosis. Arch Neurol. 2011;68(11):1440-6.

2. Nijssen J, Comley LH, Hedlund E. Motor neuron vulnerability and resistance in amyotrophic lateral sclerosis. Acta Neuropathologica. 2017;133(6):863-85.

3. Merrilees J, Klapper J, Murphy J, Lomen-Hoerth C, Miller BL. Cognitive and behavioral challenges in caring for patients with front temporal dementia and amyotrophic lateral sclerosis. Amyotrophic Lateral Sclerosis. 2010;11(3):298302.

4. Saudagar R, Garge L. Amyotrophic Lateral Sclerosis: An Overview. J Drug Deliv Ther. 2019;9(3):613-6.

5. Gordon PH. Amyotrophic lateral sclerosis: an update for 2013 clinical features, pathophysiology, management and therapeutic trials. Aging and Disease. 2013;4(5):295.

6. McCrate ME, Kaspar BK. Physical activity and neuroprotection in amyotrophic lateral sclerosis. Neuromolecular Med. 2008;10(2):108-17.

7. Zarei S, Carr K, Reiley L, Diaz K, Guerra O, Altamirano PF, et al. A comprehensive review of amyotrophic lateral sclerosis. Surg Neurol Int. 2015;6.
8. Oliveira AS, Pereira RD. Amyotrophic lateral sclerosis (ALS): Three letters that change the people's life. For ever. Arquivos De Neuro-psiquiatria. 2009;67(3A):750-82

9. Günther R, Richter N, Sauerbier A, Chaudhuri KR, Martinez-Martin P, Storch A, et al. Non-motor symptoms in patients suffering from motor neuron diseases. Front Neurol. 2016;7:117.

10. Jeffery D, Fish AF. A Journey with Amyotrophic Lateral Sclerosis. J Christ Nurs. 2018:35(3):152-9

11. Martínez HR, Escamilla-Ocañas CE, Hernández-Torre M. Non-motor neurological symptoms in patients with amyotrophic lateral sclerosis. Neurologia. 2018;33(7):474.

12. Orsini $M$, Oliveira $A B$, Nascimento $O J$, Reis $C H$, Leite MA, DeSouza JA, et al. Amyotrophic lateral sclerosis: New perpectives and update. Neurol Int. $2015 ; 7(2)$.

13. Simmons Z. Management strategies for patients with amyotrophic lateral sclerosis from diagnosis through death. Neurologist. 2005;11(5):257-70.

14. Albassam AA, Iqbal MZ, Al-Saikhan FI, Salah-Ud-Din Khan, Iqbal MS. Attitude of future healthcare professionals towards Ebola virus disease. Med Sci. 2020;24(106):3901-10

15. Iqbal MS, Iqbal MZ. Attitude of Healthcare Students towards Japanese Encephalitis. J Pharm Res Int. 2020;32:79-86

16. Panthee S, Panthee B, Shakya SR, Panthee N, Bhandari DR, Bell JS. Nepalese pharmacy students' perceptions regarding mental disorders and pharmacy education. Am J Pharm Educ. 2010;74(5).

17. Iqbal MZ, Salah-Ud-Din Khan, Iqbal MS. Oral healthcare attitude among students of a medical university. Med Sci. 2020;24(106):3891-900.

18. Ralapanawa DM, Jayawickreme KP, Ekanayake EM, Kumarasiri PV. A study on the knowledge and attitudes on advanced life support among medical students and medical officers in a tertiary care hospital in Sri Lanka. BMC Res Notes. 2016;9(1):462

19. Naveed S, Hameed A, Nadeem SM. Knowledge of Amyotrophic Lateral Sclerosis (ALS) in Pharmacy Students. Brain Disord Ther. 2014;3(147):2.

20. Iqbal MS, lqbal MZ, Rajan S, Ahmed NJ. Evaluation of Drug-related Knowledge and Clinical Skills among Future Healthcare Professionals. J Pharm Res Int. 2020;32:44-50.

Article History: Submission Date : 29-04-2020; Revised Date : 26-07-2020; Acceptance Date : 16-11-2020.

Cite this article: Iqbal MZ, Khan SUD, lqbal MS. Correlates of Attitude towards Amyotrophic Lateral Sclerosis (ALS) among Health Care students - A Crosssectional Study Findings. Int. J. Pharm. Investigation, 2020;10(4):604-7. 